\title{
Heartbeat: phenotypic heterogeneity of bicuspid aortic
} valve disease

Bicuspid aortic valve (BAV) disease is common, affecting $1 \%-2 \%$ of the entire population, with nearly all BAV patients eventually requiring aortic valve replacement, often with concurrent aortic surgery for dilation of the sinuses or ascending aorta. Although echocardiography allows easy diagnosis of the presence of BAV disease early in life, we are unable to predict disease progression or aortic dilation in an individual patient and we have no effective therapies to preserve normal valve function.

In this issue of Heart, Evangelista and colleagues ${ }^{1}$ sought to identify phenotypic predictors of valve dysfunction and aortic root dilation in a series of 802 consecutive adults diagnosed with BAV at eight tertiary care hospitals. As in previous studies, BAV leaflet morphology characterised by fusion of the right and left (RL) coronary cusps was most common (73\%), followed by fusion of the right and non-coronary cusps (24\%). Aortic regurgitation was associated with male sex and leaflet prolapse. Aortic stenosis was associated with RL valve morphology, the presence of a raphe (seen in 82\%), age, dyslipidaemia and smoking. Dilation of the ascending aorta was not associated with any specific valve morphology whereas aortic sinus dilation was associated with RL leaflet morphology, male sex, and aortic regurgitation. (figure 1)

In the accompanying editorial, Krieger and $\mathrm{Hung}^{2}$ raise the concern that "valve morphology and demographics only partially explain the clinical heterogeneity seen in patients with bicuspid aortic valve. The current paper is among the largest and highest quality studies to describe these associations. Nevertheless, even with a large sample size and a core lab to minimise misclassification bias, only relatively small (although significant) differences are seen between bicuspid valve types. Much of the remaining heterogeneity

Correspondence to Professor Catherine M Otto, Division of Cardiology, University of Washington, Seattle, WA 98195, USA; cmotto@uw.edu

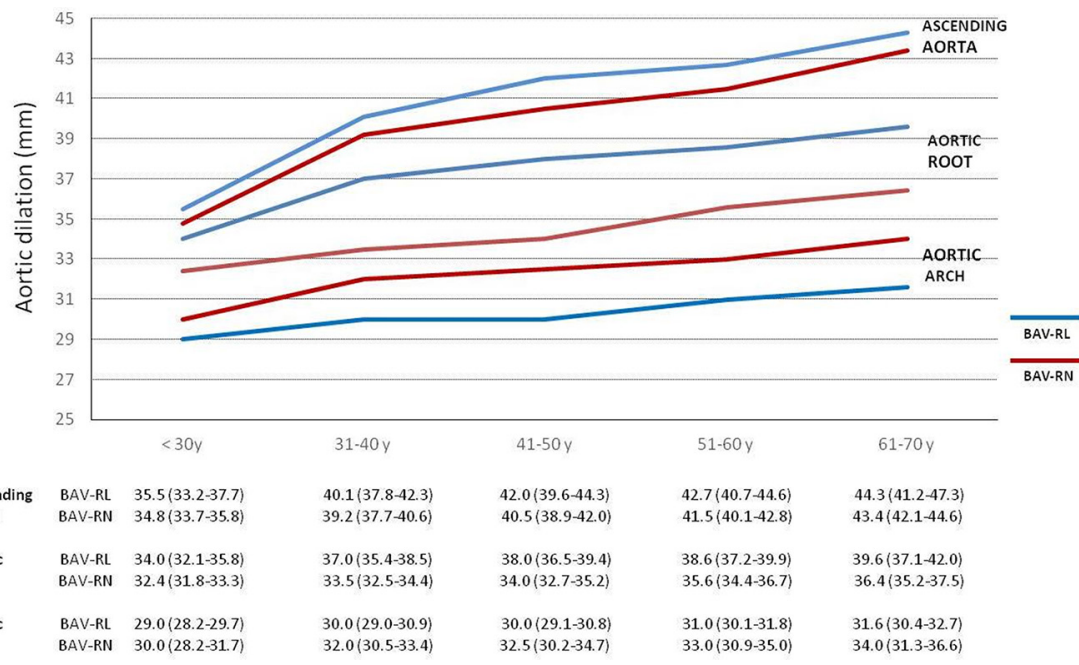

Figure 1 Aortic diameters according to age. Graph representing mean aortic diameters at the level of the aortic root, ascending aorta and aortic arch in patients with BAV-RL and BAV-RN. Note the homogeneous enlargement of the diameters over time in the three aorta segments. However, while ascending aorta diameters were similar between BAV types, aortic root diameters were consistently larger in BAV-RL and aortic arch diameters in patients with BAV-RN. Table shows mean and Cls of aortic diameters according to age at the three different aorta levels. BAV, bicuspid aortic valve; $\mathrm{RL}$, right and left; $\mathrm{RN}$, right coronary and non-coronary. is likely genetic." They go on to ask: "Can the associations described here and elsewhere help clinicians better manage patients? Unfortunately, it is unlikely. Despite the statistically significant associations between demographics, valve morphology, valve dysfunction and aortic dilation, there remains too much overlap to tailor therapy to valve type."

The success of surgical and medical therapy for congenital heart disease means that we now see more older adults or stoke who also have underlying adult congenital heart disease (ACHD). To determine if ACHD patients have unique risk factors for adverse cardiovascular events, Bokma and colleagues ${ }^{3}$ used a case-control design to match 55 ACHD patient with an acute coronary event and 56 cases with stroke to similar adults with coronary disease or a stroke who did not have ACHD. Multivariate analysis showed that in ACHD patients coronary disease presenting with coronary artery disease

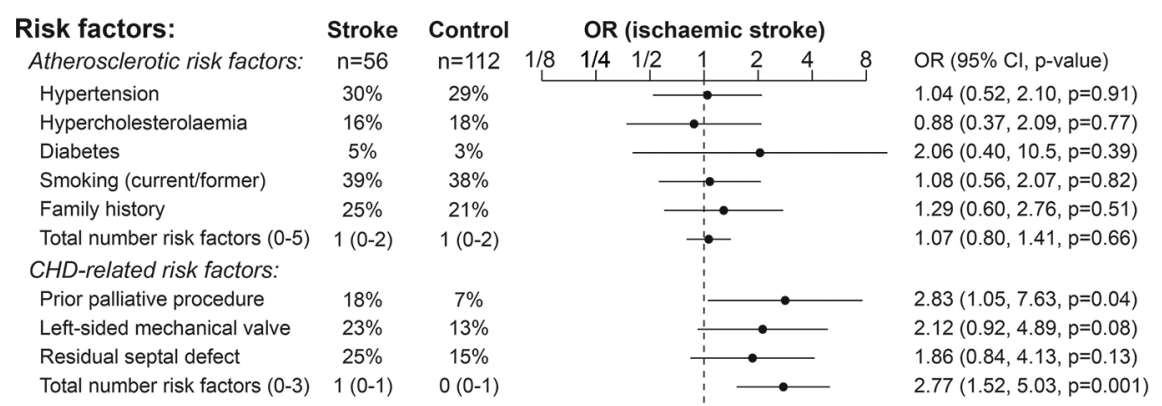

Figure 2 Factors associated with ischaemic stroke. Univariable logistic regression analysis was performed with ischaemic stroke/transient ischaemic attack as outcome variable. Forest plots displaying OR with $95 \% \mathrm{Cl}$ of different atherosclerotic and congenital heart disease (CHD)-related risk factors. Median number of risk factors displayed with IQR for both groups. 
Table 1 Pathophysiology of acquired cardiovascular disease in congenital heart disease

\begin{tabular}{|c|c|c|c|}
\hline \multicolumn{4}{|c|}{ Acquired cardiovascular diseases in ACHD } \\
\hline Stroke & & CAD & \\
\hline ACHD-related factors & Non-ACHD-related factors & ACHD-related factors & Non-ACHD-related factors \\
\hline $\begin{array}{l}\text { Previous shunt operations } \\
\text { Residual/unclosed septal defects } \\
\text { Left-sided mechanical valves } \\
\text { Arrhythmias } \\
\text { Endocarditis } \\
\text { Hypoxaemia } \\
\text { Secondary erythrocytosis } \\
\text { Iron deficiency } \\
\text { Associated syndromes } \\
\text { - Heart failure }\end{array}$ & $\begin{array}{l}\text { Age } \\
\text { Heart failure } \\
\text { Myocardial infarction } \\
\text { Diabetes mellitus } \\
\text { Arterial hypertension } \\
\text { Arrhythmias }\end{array}$ & $\begin{array}{l}\text { Congenital coronary artery } \\
\text { abnormalities } \\
\text { Previous surgical procedures } \\
\text { Compression of the left coronary } \\
\text { ostium } \\
\text { - Cyanosis }\end{array}$ & $\begin{array}{l}\text { Age } \\
\text { Arterial hypertension } \\
\text { Hypercholesterolaemia } \\
\text { Smoking } \\
\text { Obesity }\end{array}$ \\
\hline
\end{tabular}

$\mathrm{ACHD}$, adult congenital heart disease; CAD, coronary artery disease.

was associated with conventional athero- suggesting stroke was due to a cardiac sclerotic risk factors. In contrast, stroke embolic event in many of these patients was associated with previous shunt oper- (figure 2).

ations, residual or unclosed septal defects Giannakoulas and Ntiloudi ${ }^{4}$ point out and left sided mechanical heart valves, that ACHD patients have a high risk of

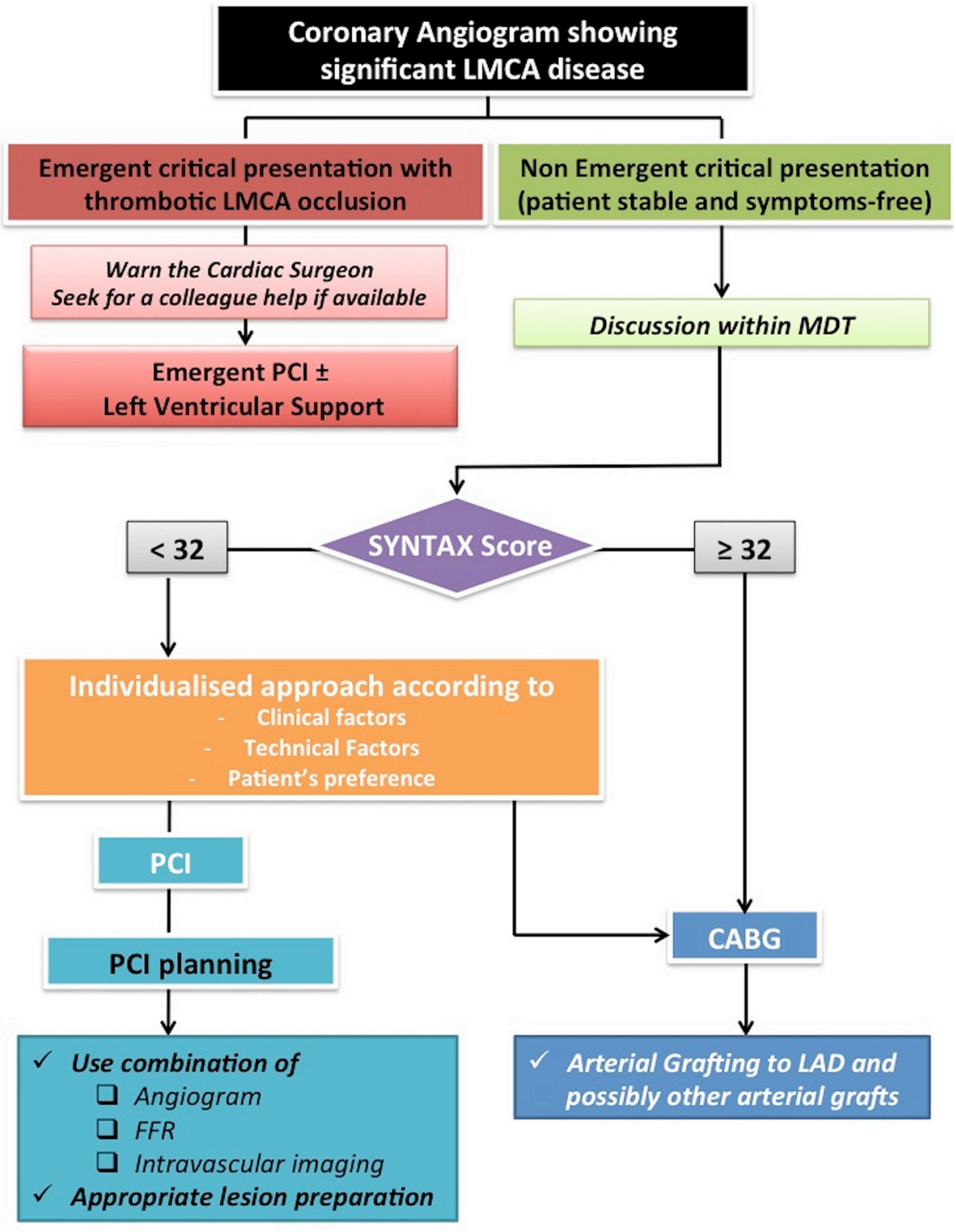

Figure 3 Decision-making aid for the management of patients with obstructive left main stem disease. CABG, coronary bypass grafting; FFR, fractional flow reserve; $L A D$, left anterior descending; LMCA, left mainstem coronary artery; MDT, multidisciplinary team; $\mathrm{PCl}$, percutaneous coronary intervention; SYNTAX, Synergy between PCI with Taxus and Cardiac Surgery. stroke compared with the general population. As shown in the study by Bokma and colleagues, ${ }^{3}$ these patients have additional risk factors for cardioembolic events related to their underlying ACHD anatomy and previous interventions (table 1). The pathophysiology of adverse cardiovascular events in ACHD patients has implications for therapy-first, appropriate risk factor evaluation and primary prevention for coronary disease is essential and, second, we need to address the gap in current recommendations regarding antiplatelet versus anti-coagulant therapy to prevent stroke in ACHD patients, given the additional risk factors for cardioembolic events in this patient group.

The role of coronary angiography in patients with worsening heart failure remains controversial. In an observational study of 2516 heart failure patients, $12.5 \%$ underwent coronary angiography within 30 days of worsening heart failure symptoms. Factors associated with performance of coronary angiography included hospital admission, an overt acute coronary syndrome, a higher troponin level, younger age and better renal function. Patients who underwent coronary angiography had a lower risk of death (adjusted $\mathrm{HR}=0.59$, 95\% CI 0.43 to $0.80, p=0.001)$ compared with those who did not undergoing coronary imaging. The risk of adverse events was higher in the $34 \%$ with a coronary stenosis compared with those with no significant stenosis (adjusted HR for the primary outcome $=1.71,95 \% \mathrm{CI} 1.10$ to 2.64, $\mathrm{p}=0.016$ ).

In an editorial, Petri and Rocchiccioli ${ }^{6}$ note that previous studies in other populations have shown a similarly low rate of coronary angiography in patients with worsening heart failure. On reviewing the literature and the current study by Ferreira and colleagues, ${ }^{5}$ they conclude: "the inescapable truth is that little is known of the role of coronary angiography in 
the diagnosis and treatment of acute or chronic heart failure. There are currently a few answers, but many more questions."

The Education in Heart article ${ }^{7}$ in this issue discusses coronary stenting for left mainstem coronary artery artery (LMCA) disease. A question and answer format summaries the three principal clinical trials: the Synergy between PCI with Taxus and Cardiac Surgery Substudy (SYNTAX), the Nordic-Baltic-British Left Main Revascularisation (NOBLE) and Evaluation of Xience Versus CABG for Effectiveness of Left Main Revascularization (EXCEL) studies. The authors conclude: 'With the simultaneous publication of NOBLE and EXCEL studies in 2016, evidence regarding revascularisation in LMCA disease has expanded dramatically. Both trials were large and well conducted, but because of their contrasting results and potential limitations, a uniform recommendation about the relative role of stenting compared with CABG in LMCA disease is inappropriate. A possible algorithm to support and aid the decision-making process is shown in figure 3."

Check out the Image Challenge question in this issue. A unique clinical presentation with diagnostic echo images! $!^{8}$

Competing interests None declared.

Patient consent Not required.

Provenance and peer review Commissioned; internally peer reviewed.

(C) Article author(s) (or their employer(s) unless otherwise stated in the text of the article) 2018. All rights reserved. No commercial use is permitted unless otherwise expressly granted.

\section{(D) Check for updates}

To cite Otto CM. Heart 2018;104:541-543.

Heart 2018;104:541-543.

doi:10.1136/heartjnl-2018-313186

\section{REFERENCES}

1 Evangelista A, Gallego P, Calvo-Iglesias F, et al. Anatomical and clinical predictors of valve dysfunction and aortic dilation in bicuspid aortic valve disease. Heart 2018;104:566-73.

2 Krieger EV, Hung J. Bicuspid aortic valve type: it takes two. Heart 2018:104:544-5.

3 Bokma JP, Zegstroo I, Kuijpers JM, et al. Factors associated with coronary artery disease and stroke in adults with congenital heart disease. Heart 2018;104:574-80.

4 Giannakoulas G, Ntiloudi D. Acquired cardiovascular disease in adult patients with congenital heart disease. Heart 2018;104:546-7.

5 Ferreira JP, Rossignol P, Demissei B, et al. Coronary angiography in worsening heart failure: determinants, findings and prognostic implications. Heart 2018;104:606-13

6 Petrie MC, Rocchiccioli P. Coronary angiography in heart failure: when and why? Uncertainty reigns. Heart 2018;104:548-9.

7 De Maria GL, Patel N, Banning AP. Obstructive left main stem coronary disease: is it time to recommend coronary stenting? Heart 2018;104:614-20.

8 Wang Y-C, Huang C-W, Lin T-W. Acute heart failure with new-onset continuous murmur in a 26-year-old man. Heart 2018;104:593. 


\section{Correction: Heartbeat: phenotypic heterogeneity of bicuspid} aortic valve disease

Otto CM. Heartbeat: phenotypic heterogeneity of bicuspid aortic valve disease. Heart 2018;104:541-3.

In this Heartbeat the sentence 'Aortic stenosis was associated with RL valve morphology' should read 'Aortic stenosis was associated with RN valve morphology'.

(c) Article author(s) (or their employer(s) unless otherwise stated in the text of the article) 2018. All rights reserved. No commercial use is permitted unless otherwise expressly granted.

Heart 2018;104:e5. doi:10.1136/heartinl-2018-313186corr1

(D) Check for updates 